\title{
Should We Judge PHCs by Only IPHS Guidelines or Probe Further?
}

\section{Rupa Sarkar ${ }^{1}$, Mahesh $\mathrm{E}^{2}$}

${ }^{1}$ Adjunct Faculty, PhD Scholar, CHRIST (Deemed to be University), Hosur Road, Bangalore; ${ }^{2}$ Assistant Professor, Department of Economics, CHRIST (Deemed to be University), Hosur Road, Bangalore

\begin{tabular}{|c|c|c|c|c|c|c|c|c|}
\hline Abstract & Introduction & Methodology & Results & Conclusion & References & Citation & \multicolumn{2}{|c|}{ Tables / Figures } \\
\hline \multicolumn{9}{|c|}{ Corresponding Author } \\
\hline \multicolumn{8}{|c|}{$\begin{array}{l}\text { Rupa Sarkar, Department of Economics, CHRIST (Deemed to be University), Hosur Road, Bangalore, } \\
\text { Karnataka - } 560029 \\
\text { E Mail ID: rupasneha72@gmail.com }\end{array}$} & 回评回 \\
\hline
\end{tabular}

\section{Citation}

Sarkar R, Mahesh E. Should We Judge PHCs by Only IPHS Guidelines or Probe Further?. Indian J Comm Health. 2020;32(2):464-467.

Source of Funding: Nil Conflict of Interest: None declared

\section{Article Cycle}

Received: 04/04/2020; Revision: 11/05/2020; Accepted: 29/05/2020; Published: 30/06/2020

This work is licensed under a Creative Commons Attribution 4.0 International License.

\section{Abstract}

Background: Indian Public Health Standards (IPHS) evaluates supply side compliance of Primary Health Centers (PHCs). Patient Satisfaction (PS) on the other hand, assesses the demand side. Objective: Examining the supply side compliance and relating it to PS in the domain of Reproductive Health (RH). Methods: Using multistage stratified sampling, six rural and three urban PHCs in sub-districts, Ramanagara and Channapatna, in District Ramanagara, state of Karnataka, India, were chosen. Information collected using IPHS proforma for PHCs was compared with PS questionnaire (PSQ 18) data, collected from 398 patients visiting these facilities. Results: Using descriptive and inferential analysis, sub-optimal compliance levels in ease of access, physical \& human infrastructure, patient data and usage of untied funds was found. Existing behavioral compliance was found to be optimal. These findings were in alignment with PS findings. Conclusion: Results call for PHC capacity building, incentivization and a crucial need to look into PS side, before passing judgement about performance standard.

\section{Keywords}

PHC; IPHS; Health Standard Compliance; Reproductive Health; Facility Guidelines

\section{Introduction}

A 2015 Malaysian study using cross-sectional convenient sample of outpatients revealed correlation among health infrastructure and patient satisfaction.(1) A study using World Health Organization (WHO) quality assessment framework of patient satisfaction, adopted from the 1988 Donabedian model (framework of healthcare quality evaluation by examining service provision), successfully correlated healthcare infrastructure by measuring outpatient experiences in 2018.(2) IPHS a similar quality assessment supply side framework, is equally mindful of the demand side of healthcare, as becomes clearly evident from its proforma of compliance domains. Although many IPHS guided district level PHC compliance studies were undertaken earlier in states of Andhra Pradesh, Himachal Pradesh, Gujarat, West Bengal and Karnataka, our study findings reflect the equation between supply and demand of healthcare facilities from solely $\mathrm{RH}$ perspective.

\section{Aims \& Objectives}

To examine the alignment between the supply side of PHCs with patient satisfaction they yield in order to cater to their demand side.

\section{Material \& Methods}

Study type: Cross-sectional study of PHCs and Patients utilizing these facilities.

Study Population: 20000-30000 Patients of RH age group (15-49) visiting these nine PHCs seeking treatment more than once in last one year (May 2017-18) for $\mathrm{RH}$ related issues of pregnancy, neo-natal, family planning, abortion, miscarriage and $\mathrm{RH}$ disorders.

Study Duration: Seeking permission, data collection, analysis and interpretation continued from March 2018 to October 2019.

Sample Size and Selection Criteria: State of Karnataka in the Southern Peninsular India, district Ramanagara and sub-districts (taluka) Ramanagara and Channapatna were chosen based on their mediocrity of $\mathrm{RH}$ indicators. The specific PHC facilities were chosen by Medical Officers 
(MO) after instruction of District Health \& Family Welfare

Office (DHFWO) keeping in mind their physical location and staff experience. Rural PHCs (RPHCs) chosen were of Laksmipura, Kanva, Kootagal, Kodamballi, Honganur and Jagadapura. Urban PHCs (UPHCs) were Mehboobnagar, Rayardoddi \& S S Mohalla. First three RPHCs were from Ramanagara taluka and the following three were in Channapatna. First two UPHCs were in Ramanagara taluka and the third one in Channapatna.

For arriving at a sample size of patients for demand side survey, we used the information provided by the nine PHCs, that a total $2341 \mathrm{RH}$ related cases were treated in OPD and in-patient cases in the month of May 2018. Based on this, population for last one year was calculated at maximum of 30000 , sample size was estimated at 380 (Confidence interval 5 \& Confidence Level of 95\%). Total 398 patients were finally selected for the survey analysis. Sample demographic classification was based on gender (males 22\% \& females 78\%), age groups (15-25 (29\%), 26$35(34 \%)$ \& 36-49 (37\%)), religion (Hindus 47\%, Muslims $52 \% \&$ others $1 \%$ ), medical background ( $\mathrm{RH} 38 \%$, pregnancy $17 \%$, neo-natal $16 \%$, family planning $17 \%$ \& abortion/miscarriage $12 \%)$, number of visits in last one year (2-4 (27\%), 5-8 (40\%) \& >8 (33\%)), type of visits (OPD $40 \%$, OPD + Inpatient $54 \%$ \& Inpatient $6 \%$ ), residing distance from facility (<2 (18\%), 2-5 (20\%), 5-10 (27\%), 10 $25(27 \%) \&>25 \mathrm{kms} 8 \%$ ), education levels (illiterate $4 \%$, primary $47 \%$, secondary $35 \% \&$ tertiary $15 \%)$, employment type (regular salaried $24 \%$, daily waged $34 \%$, self-employed $37 \%$ \& unemployed $5 \%$ ), income levels (<0.1 (20\%), 0.1-0.3 (37\%) , 0.3-0.5 (35\%) \& > 0.5 million INR per annum (7\%)) and insurance status (insured 25\% \& uninsured 75\%).

Institutional Ethical Committee \& Ethical concerns: Prior Institutional Ethical Committee permission was sought before the study was undertaken (CU: CFR: 01/04/18). Post briefing to $\mathrm{MO}$ and staff, duly attested and filled by senior staff, the questionnaires were collected from PHCs. For the Demand side survey, after orientation about study details, privacy concerns and interview environment, verbal consent was taken from all participants. Minors and illiterates were interviewed in the presence of another adult family member. Data was aggregated maintaining complete privacy of personal details.

Strategy for Collection: Reproductive and Child Health (RCH) survey questionnaire for PHCs, used in District Level Health Survey (DLHS), was used to collect initial PHC details in RH domain. Later the IPHS proforma prescribed for same domains was used to compare compliance levels. IPHS proforma used to collect the supply side compliance, had items related to Infrastructure, Services, Training, Quality control and Behavior. PSQ 18 standardized questionnaire (by Marshall and Hays) used for collecting PS, had seven sub-scales of General Satisfaction, Technical Quality, Interpersonal Manner, Communication, Financial
Aspects, Time spent with Doctor and Accessibility \& Convenience.

Data Analysis: Data was processed for descriptive (Mean $\& S D$ ) and inferential (chi square) statistics using Excel and SPSS 20.

\section{Results}

All the six Rural PHCs had a range of $13-25 \mathrm{kms}$ distance from secondary healthcare. None barring one, had birthing facilities or operating $24 / 7$. Only $66 \%$ of RPHCs had 6 beds as per guidelines. 30\% didn't have staff nurse. $11 \%$ didn't have a female Medical Officer. None had Female Health Assistant. $22 \%$ had no Male Health Assistant. Three Urban PHCs which were catering to twice or thrice the amount of population recommended by IPHS were having only 2-3 beds and not operating 24/7. Untied funds, a quality enhancing tool, was either partially used or information wasn't provided indicating either documentation issues or non-transparency. Moreover, the ratings of facilities, a deciding factor for release of funds and a lot of procedural formalities, either delayed or complicated its usage. $100 \%$ Behavioral compliance was being met. Demand side findings are tabulated at the end after references.

(Table 1) PS shows the technical quality, general satisfaction gained from the medical care in general and accessibility is lowest. These items were dominated by questions about infrastructure, its advancement level along with access. This finding is in alignment with IPHS compliance findings. All behavioural aspects show higher satisfaction which also is in conformity with IPHS findings. (Table 2) Chi square results show strong association existing between Income level, Insurance coverage, Type of visit (at $p<0.00$ l), Employment type (at $p<0.05$ ), religion and patient satisfaction. We found no significant association between age, gender, number of visits, medical background and patient satisfaction levels. The possible reason behind religion being dominant factor may be either higher utilization levels or lower ease of access arising out of lack of awareness or discrimination faced. Economic background like income, salary type and insurance affects indirectly amount of dependence on public healthcare, so yields dominant influence. Type of visit explores the length of stay and infrastructural amenities directly so might be a significant influence leading to stronger association.

\section{Discussion}

Supply side: First finding supported by previous studies, indicate inaccessibility barriers caused by far away locations, infrastructural shortage (Personnel, Drugs, certain Pathology tests, specific facilities like OT, Radiology, Birthing, and Inpatient).(3 456 ) This led to long commutes, wastage of time, longer uncertain waiting periods, monetary loss from private health expenditures, wage loss for daily wage earners and limited treatment choices. Second finding throws light on PHCs not being 
able to provide accurate quantitative data on patient details as stressed earlier by another study.(7) Third finding was regarding untied funds usage where there seemed to be either partial usage or an information blanket. We found Arogya Raksha Samiti (ARS) handling this component appropriately, taking along the local community members into confidence.

Demand side: Statistically significant demographic variables clearly indicated economic factors having dominance over personal factors. As found earlier Length of stay, Employment type, Income level and type of healthcare sought were crucial.(2) Lowest satisfaction was found in Technical Quality, Accessibility and Convenience showing coherence with supply side findings as corroborated by another earlier study.(8) Providers need to shift their focus towards these unmet demands. Patients held PHC staff behavior, support, communication, consultation quality in very high esteem from both demand and supply sides which calls for appropriate incentivisation as reported earlier.(9)

\section{Conclusion}

PHCs facing multiple supply side challenges, yet serve as backbone of Indian Health system. Dedicated human resource indicates involvement. Lagging physical resources need to be made available to fulfil the structural challenges by initiating key public investments at grassroot level.

\section{Recommendation}

There is a strong need for intervention in accessibility barriers caused by infrastructural shortage. Being mindful of patient's gender necessities through suitable staffing at facilities would greatly help. Coordinated training in data entry, closer collaboration with academic institutions and IT sector are necessitated for training updates. Strengthening of village communities crucial to take initiatives to project their needs and suggest expenditures under untied funds. Policy framers need to reinforce meritorious staff contributions by suitable incentivization including career growth, personal development and monetary rewards as reiterated earlier.(10)

\section{Limitation of the study}

Larger number of PHCs and more sub-districts could strengthen in generalising results.

\section{Relevance of the study}

Till now healthcare facilities in $\mathrm{RH}$ have been evaluated from either supply or demand side. This study has examined the purpose of these related perspectives together for service alignment in $\mathrm{RH}$.

\section{Authors Contribution}

RS: conceptualization, designing, implementation and analysis. ME: reviewing.

\section{Acknowledgement}

The extensive support of DHFWO and Medical staff of Ramanagara District is deeply appreciated. The study wouldn't be possible without the contribution of the participants of the survey.

\section{References}

1. Ganasegeran K, Perianayagam W, Manaf RA, Jadoo SA, AI-Dubai SA. Patient satisfaction in Malaysia's busiest outpatient medical care. ScientificWorldJournal. 2015;2015:714754. doi: 10.1155/2015/714754. Epub 2015 Jan 12. PubMed PMID: 25654133; PubMed Central PMCID: PMC4306375.[PubMed]

2. Jena $S \&$ Gupta M. A survey of patient satisfaction of patients attending a psychiatry outpatient clinic at a tertiary care centre. International Journal of Community Medicine And Public Health 2018; 5(5):2026-30.

3. Kumar S, Dansereau EA \& Murray CJ. Does distance matter for institutional delivery in rural India? Applied Economics 2014;46(33):4091-103.

4. Osiya DA, Ogaji DS, \& Onotai L. Patients' satisfaction with healthcare: comparing general practice services in a tertiary and primary healthcare settings. Nigerian Health Journal 2017; 17(1).ISSN:1597-4292.

5. Sriram S. Availability of infrastructure and manpower for primary health centers in a district in Andhra Pradesh, India. J Family Med Prim Care. 2018 Nov-Dec;7(6):1256-1262. doi: 10.4103/jfmpc.jfmpc_194_18. PubMed PMID: 30613507; PubMed Central PMCID: PMC6293956.[PubMed]

6. Chauhan R, Mazta SR, Dhadwal DS, Sandhu S. Indian public health standards in primary health centers and community health centers in Shimla District of Himachal Pradesh: A descriptive evaluation. CHRISMED Journal of Health and Research. 2016 Jan 1;3(1):22.

7. A vision for primary health care in the 21st century: towards universal health coverage and the Sustainable Development Goals. Geneva: World Health Organization and the United Nations Children's Fund (UNICEF), 2018 (WHO/HIS/SDS/2018.X). Licence: CC BY-NC-SA 3.0 IGO. Available from: https://www.who.int/docs/default-source/primaryhealth/vision.pdf.

8. Asraf M, Asraf F, Rahman A, Khan R. Assessing women's satisfaction level with maternity services: Evidence from Pakistan. Int J Collab Res Intern Med Public Health 2012;4:1821-51.

9. Karnataka Evaluation Authority. Bangalore: Performance Evaluation Study of NRHM in Karnataka-Project Report; Grassroots Research and Advocacy Movement, Mysore, Karnataka, India. Available from:

http://kea.karnataka.gov.in/sites/default/files/Evaluation\%20of\% 20the\%20performance\%20evaluation\%20study\%20of\%20NRHM \%20in\%20Karnataka\%20.pdf.

10. Agarwal P \& Biswas R. Satisfaction of patients attending a rural hospital of Darjeeling district in West Bengal, India. International Journal Of Community Medicine And Public Health 2017;4(6), 1932-37. 


\section{Tables}

\section{TABLE 1 PATIENT SATISFACTION SUB-COMPONENT LEVELS}

\begin{tabular}{|c|c|c|c|c|c|c|c|}
\hline $\begin{array}{l}7 \text { sub-scale } \\
\text { scores }\end{array}$ & $\begin{array}{l}\text { General } \\
\text { Satisfacti } \\
\text { on }\end{array}$ & $\begin{array}{l}\text { Technical } \\
\text { Quality }\end{array}$ & $\begin{array}{c}\text { Interpersonal } \\
\text { Manner }\end{array}$ & $\begin{array}{l}\text { Communic } \\
\text { ation }\end{array}$ & $\begin{array}{c}\text { Financial } \\
\text { Aspect }\end{array}$ & $\begin{array}{l}\text { Time Spent } \\
\text { with Doctor }\end{array}$ & $\begin{array}{c}\text { Accessibility \& } \\
\text { Convenience }\end{array}$ \\
\hline $\begin{array}{l}\text { Average } \\
\text { score/5* }\end{array}$ & 2.78 & 2.9 & 3.62 & 3.49 & 3.52 & 3.23 & 3.17 \\
\hline $\begin{array}{l}\text { Percentage } \\
\text { Satisfaction }\end{array}$ & 55.6 & 57.8 & 72.3 & 69.8 & 70.0 & 64.6 & 63.4 \\
\hline \multicolumn{8}{|c|}{$\begin{array}{l}\text { Computed from SPSS output of Survey Data } \\
\text { questionnaire scoring key }\end{array}$} \\
\hline
\end{tabular}

\section{TABLE 2 CHI-SQUARE TEST OF SIGNIFICANCE OUTPUT}

Independent Variables

Pearson Chi-Square Significance

Gender

0.18

Age

0.85

Education Level

0.21

Income Level $0.000^{* *}$

Number of Visits 0.13

Medical Background 0.47

Insurance Coverage $0.000^{* *}$

Residential Distance from PHC 0.3

Religion $0.03^{*}$

Type of Visits $0.003^{* *}$

Employment Type $0.03 *$

Computed from SPSS output of Survey Data ${ }^{*} p<0.05 * * p<0.01$ 